\title{
OBITUARY
}

\section{Jan Daniel Smith, 6 February 1939 - 6 September 2019}

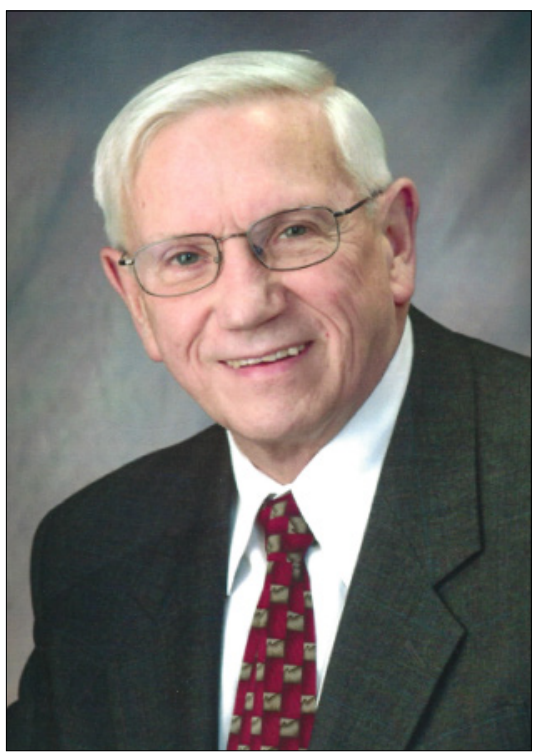

Dr Jan Daniel Smith died in Pittsburgh, USA, on 6 September 2019 after a long battle with interstitial pulmonary fibrosis. Born in Pretoria, South Africa (SA) on 6 February 1939, he matriculated at Pretoria Boys High School and graduated MB ChB at the University of Pretoria in 1961 at the age of 22 years.

Jan had a very rich academic career. After internship at McCord Hospital, Durban, KwaZulu-Natal, he worked in paediatrics, internal medicine and anaesthetics at Addington and King Edward VIII hospitals in Durban. He specialised as an anaesthesiologist at Peter Bent Brigham Hospital in Boston, USA, and completed fellowships in critical care and pulmonology in a multidisciplinary critical care medicine training programme at the University of Pittsburgh Medical Center (UPMC). In 1969 , he returned to SA for further training in internal medicine at Groote Schuur Hospital, Cape Town. In 1971, he left for Pittsburgh to complete training in internal medicine, and was appointed to the anaesthesiology department. He subsequently held various appointments in pulmonary and internal medicine, and in anaesthesiology in Iowa, Texas, Nebraska and Ohio before returning to Pittsburgh in 1987, where he was appointed chief of anaesthesiology at UPMC Presbyterian, a position he held until 1996. During this time, he earned a Diploma in Tropical Medicine and Hygiene from the Royal College of Physicians. He subsequently became chief of anaesthesiology and medical director at UPMC Beaver Valley, and in 2000 moved to Palermo, Sicily, where he helped to establish a UPMC transplantation centre. In 2002, he returned to UPMC as vice-chair for clinical operations. In 2009, he was appointed associate medical director at UPMC Beacon Hospital in Dublin, Ireland.
After his retirement, he continued in a parttime appointment at UPMC in Pittsburgh. The Allegheny County Medical Society honoured him with an award for volunteer work, and a classroom was named after him in the UPMC Department of Anesthesia.

SA always remained close to his heart. $\mathrm{He}$ visited frequently to spend time with family and friends and to go on safaris, and regularly attended the SA Society of Anaesthesiologists congresses. He hosted numerous South Africans, who gained experience at UPMC in liver surgery, anaesthesiology, otolaryngology, and transplantation and neurosurgery. He was also involved with the US President's Emergency Plan for AIDS Relief (PEPFAR), worked as a volunteer in sub-Saharan Africa, and was appointed extraordinary professor of medicine at the University of Pretoria School of Medicine.

Jan is survived by his beloved wife, Jeanette Niemeyer Smith, to whom he was married for 56 years, his brother Sydney (married to Liesje), 3 children, Robert (married to Kathy van Stone), Andrew (married to Sandra Espinosa) and Anita (married to Dr Andrew Murray), and 9 grandchildren.

Peter C Gordon, Johannes J Fagan University of Cape Town, South Africa peter.gordon@uct.ac.za 